\title{
Dr. Hiroaki Takekura. A tribute to a life of science
}

\author{
Clara Franzini-Armstrong
}

Published online: 20 May 2011

(C) Springer Science+Business Media B.V. 2011

Dr. Hiroaki Takekura, Professor at the National Institute of Fitness and Sports in Kanoya, Japan, an electron microscopist of world fame, passed away on 19 February, 2011, at the age of 50 .

Dr. Takekura was an undergraduate at Tokyo Gakugei University (1980-1984) and later continued his graduate education in the Department of Physiology, St. Marianna University School of Medicine, with Prof. Toshitada Yoshioka, obtaining a doctor degree in medicine in 1995. He started as a research assistant in 1988 and later became associate professor (1995) and full professor (2002) at the National Institute of Fitness and Sports.

His interest in sports medicine and later specifically in skeletal muscle was stimulated by a remarkable high school athletic performance. He was involved in a variety of sports and was very proud of his $2 \mathrm{~m}$ record in the track and field competitions' high jump. Dr. Takekura's training with Prof. Yoshioka shaped the course of his future scientific research. He learned to use electron microscopy in establishing structure-function correlations, and particularly in studying the determinants of fibre type specializations and their changes during differentiation and pathology. With Prof. Yoshioka, he published several papers using a sophisticated approach to relate structure and function at the single muscle fiber

C. Franzini-Armstrong $(\square)$

Department of Cell and Developmental Biology,

University of Pennsylvania, Philadelphia,

PA 19104-6058, USA

e-mail: armstroc@mail.med.upenn.edu level. He later followed with a rich series of publications dealing with muscle fibres responses to a variety of normal and pathological challenges. The hallmarks of his publications are stunning electron micrographs and stringent morphometric data. He has left a legacy of extremely relevant observations that create a baseline for the description of most muscle pathology in relation to fibre type.

Over a long period of interaction with my laboratory at the University of Pennsylvania, Dr. Takekura (Hiro to his friends) developed an additional interest in the molecular basis for excitation-contraction coupling. He published numerous landmark papers, most important his collaboration with Dr. Kurt G. Beam in the identification of the $\mathrm{T}$ tubule tetrads with the voltage sensors of e-c coupling (Biophys J 67:793-804, 1994) and with Dr. Hiroshi Takeshima, describing triad architecture in the first mouse model carrying an engineered null mutation for the ryanodine receptor (PNAS 92:3381-3385, 1995).

Hiro never ceased to work at the research that was his major passion. His last paper was published very recently in J Muscle Res Cell Motility. Despite a very heavy teaching load, he maintained a high productivity while holding to standards of hard work and high scientific integrity. He transmitted his work ethics to 21 undergraduate and nine graduate students, maintaining a cheerful atmosphere of fellowship. Hiro is missed by his students at the National Institute of Fitness and Sports in Kanoya, Japan; by his mentor Prof. Yoshioka; by his colleagues and numerous collaborators in Japan (Profs. H. Kurata, F. Ogita, and N. Kasuga) and most of all by his wife of many years, Setsuko Takekura. Hiro was a wonderful, generous person, full of enthusiasm and we cannot get used to the thought that he will not arrive again to visit us from Japan, all ready to go on to the next project. 


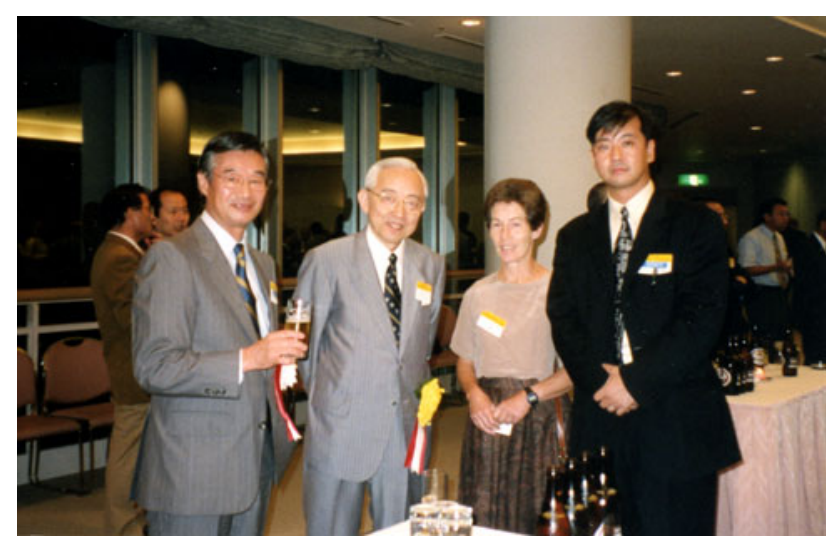

The picture was taken at the 53rd Annual Meeting of the Japanese Society of Physical Fitness and Sports Medicine in Yokohama city, chaired by Prof. T Yoshioka and shows Dr Takekura at left with (from left to right): Prof. T Yoshioka (Chairman of Physiology, currently President, Hirosaki Gakuin University); Prof. K Hasegawa (currently President, St. Marianna University of School of Medicine) and Dr. C. Franzini-Armstrong, University of Pennsylvania. 